\title{
Effects on the distortion of Inconel 718 components along a hybrid laser-based additive manufacturing process chain using laser powder bed fusion and laser metal deposition
}

\author{
Eckart UhImann ${ }^{1,2} \cdot$ Jan Düchting ${ }^{1} \cdot$ Torsten Petrat $^{2} \cdot$ Erwin Krohmer $^{1}$ (D) $\cdot$ Benjamin Graf $^{2} \cdot$ Michael Rethmeier $^{1,2}$
}

Received: 1 September 2020 / Accepted: 31 January 2021 / Published online: 17 February 2021

(c) The Author(s) 2021

\begin{abstract}
The combination of laser powder bed fusion (LPBF), known for its geometrical freedom and accuracy, and the nozzle-based laser metal deposition process (LMD), known for its high build-up rates, has great potential to reduce the additive manufacturing times for large metallic parts. For the industrial application of the LPBF-LMD hybrid process chain, it is necessary to investigate the influence of the LMD process on the LPBF substrate. In addition, the build plate material also has a significant impact on the occurrence of distortion along the additive manufacturing process chain. In the literature, steel build plates are often used in laser-based additive manufacturing processes of Inconel 718, since a good metallurgical bonding can be assured whilst reducing costs in the production and restoration of the build plates. This paper examines the distortion caused by LMD material deposition and the influence of the build plate material along the hybrid additive manufacturing process chain. Twin cantilevers are manufactured by LPBF and an additional layer is subsequently deposited with LMD. The distortion is measured in the as-built condition as well as after heat treatment. The effect of different LMD hatch strategies on the distortion is determined. The experiments are conducted using the nickel-base alloy Inconel 718. The results show a significant influence of LMD path strategies on distortion, with shorter tool paths leading to less distortion. The remaining distortion after heat treatment is considerably dependent on the material of the build plate.
\end{abstract}

Keywords Laser powder bed fusion - Directed energy deposition - Laser metal deposition · Distortion · Heat treatment

\section{Introduction}

Additive manufacturing processes have become very popular in recent years. The new geometrical freedom of design has a great potential to overcome the limitations posed by conventional manufacturing processes, and therefore, it becomes possible to focus on the component function. The great potential and the continuous improvement of the processes led to an increased usage in the industrial environment, as indicated in the annual Wohlers Report [1]. However, manufacturing costs and process durations are still

Erwin Krohmer

erwin.krohmer@iwf.tu-berlin.de

1 Institute for Machine Tools and Factory Management, Technische Universität Berlin, Pascalstraße 8-9, 10587 Berlin, Germany

2 Fraunhofer Institute for Production Systems and Design Technology, Pascalstraße 8-9, 10587 Berlin, Germany drawbacks of prominent additive manufacturing processes, like laser powder bed fusion (LPBF). Especially the manufacturing of large parts requires long production times, due to low build-up rates. For a modern LPBF machine, typical volume rates are around $15 \mathrm{~cm}^{3} / \mathrm{h}$ according to manufacturer specifications for alloy 718 [2]. In recent years, many efforts were made to increase the LPBF build-up rate. One approach is the usage of a multi beam system [3] as well as the increase of laser power to melt multiple layers at the same time [4]. Another approach is the hybrid additiveadditive manufacturing using the fast laser metal deposition (LMD) process for massive areas of the component and the LPBF process for areas with high geometric complexity. The LMD process features a high deposition rate. With $10 \mathrm{~kW}$ laser power, Kaierle [5] demonstrated a deposition rate of $1000 \mathrm{~cm}^{3} / \mathrm{h}$. However, the achievable geometric complexity and production accuracy of the LMD build-up is considerably lower than the LPBF process. A hybrid approach was demonstrated in previous experiments by Graf et al. [6], who printed a turbine blade, where the upper part with its grid 
structure and cooling channels was produced by LPBF and the massive fir-tree root was added in a subsequent LMD process. Thereby, the production time was reduced from $13.9 \mathrm{~h}$ to $5.4 \mathrm{~h}$. Besides the time-saving aspect, it was demonstrated that this approach can also be used to repair LPBF components with LMD [7]. The combination of the LPBF and LMD process in one hybrid additive process chain has the potential to benefit from the different advantages of each of the processes, as indicated in Table 1.

However, the combination of the processes is accompanied by technological challenges. The microstructure and the mechanical properties in the LPBF and the LMD area are different, and therefore, the fatigue behavior of the hybrid component differs as well, as shown by Uhlmann et al. [8] for Inconel 718, as well as Liu et al. [9] for Ti6A14V. Furthermore, the subsequent heat input by the LMD process can lead to distortion of the LPBF substrate. A study by Parimi [10] describes the influence of the LMD tool path on the resulting distortion of the substrate. He uses Inconel 718 as powder material and Inconel 718 rolled material as substrate. There, the lowest distortion is achieved by a tool path strategy with short tool path lengths, which are correlated to lower cooling rates. However, the stress distribution in LPBF parts is different to conventionally manufactured parts and could possibly influence the internal stress distribution and distortion in a hybrid additive manufacturing approach.

In the literature, a lot of additive manufacturing experiments with Inconel 718 are performed using build plates from different types of steel [11-13]. Since a good material connection between steel build plate and Inconel 718 part can be achieved, the usage of steel build plates instead of difficult to machine Inconel 718 build plates provides an efficient cost reduction in the additive manufacturing process chain and therefore is of industrial interest. The influence of the build plate material on residual stress in Inconel 718 components produced by LPBF was investigated by Cheng et al. [14]. However, additively manufactured metal components are often heat-treated to remove undesired residual stresses and to obtain desired mechanical properties in the component. Since the thermal-mechanical properties of Inconel 718 and the used build plate materials might vary significantly, the influence of the build plate material on the resulting distortion is an important factor that should be investigated.

More work can be found regarding the influence of LMD tool path $[15,16]$, the LPBF scanning strategies $[17,18]$ or heat treatments $[19,20]$ on the distortion or residual stress development of the single additive manufacturing processes. However, this paper contributes to a holistic understanding of the occurrence of distortion along a hybrid additive manufacturing process chain. For the presented LPBF-LMD approach, the effect of the LMD hatch strategy is investigated. Furthermore, the influence of the build plate material and post-process heat treatment on the distortion of Inconel 718 components is evaluated.

\section{Experimental methods}

To validate the distortion in hybrid LPBF-LMD components, twin cantilevers are manufactured with the LPBF process and subsequently coated with an LMD layer. In the following sections the processes and the manufacturing of the specimens are described in detail.

\subsection{The additive manufacturing processes LPBF and LMD}

The production sequence of the LPBF technology essentially consists of three repetitive steps. First, a thin layer of metal powder is placed on a platform with a wiper, as illustrated in Fig. 1a. In the second step, a focused laser beam selectively melts the powder layer and in the third step the platform is lowered by the layer thickness to begin once again with the powder deposition. These steps are repeated until the part is finished. In the LMD process, the material feed is realized by a powder nozzle, which directs the powder flow and the shielding gas towards the working plane on the base material, Fig. 1b. The laser beam is guided by the optical system through the nozzle and creates a melt pool on the base material, where single weld beads are formed after solidification of the injected powder particles.

Table 1 Comparison of the LPBF and LMD process [6]

\begin{tabular}{|c|c|c|c|c|c|}
\hline Process & $\begin{array}{l}\text { Typical laser spot } \\
\text { diameter and power }\end{array}$ & Part dimensions & Structural complexity & Substrate & Material flexibility \\
\hline LPBF & $100 \mu \mathrm{m}, 300 \mathrm{~W}$ & $\begin{array}{l}\text { Small to medium } \\
\text { (limited by pro- } \\
\text { cess chamber) }\end{array}$ & High (e.g. lattice structures) & Flat surfaces & Same powder for whole process \\
\hline LMD & $1 \mathrm{~mm}, 1 \mathrm{~kW}$ & $\begin{array}{l}\text { Medium to large } \\
\text { (limited by } \\
\text { machine working } \\
\text { area) }\end{array}$ & Limited (e.g. walls) & Freeform surfaces & In-process change of powder \\
\hline
\end{tabular}




\subsection{Fabrication of the LPBF-LMD cantilever}

The Inconel 718 LPBF cantilevers are manufactured on an SLM 250HL from SLM Solutions GmbH, Lübeck, Germany, which contains a YLR $400 \mathrm{~W}$ Yb:YAG fiber laser from IPG Pнotonics CoRporation, Oxford, USA. The LPBF process is conducted with the process parameters listed in Table 2. The used Inconel 718 powder exhibits a particle size distribution of $20 \mu \mathrm{m}$ to $63 \mu \mathrm{m}$ and is deposited with a layer thickness of $50 \mu \mathrm{m}$. For the laser exposure a hatch build-up strategy is chosen, where the scan vectors rotate by $33^{\circ}$ with each layer. To prevent oxidation during the build-up, the build chamber is filled with Argon 5.0.

The LPBF cantilever geometry with a length of $90 \mathrm{~mm}$ is shown in Fig. 2. For the experiments, 36 cantilevers are manufactured, in total. The specimens are built on three different build plate materials, with 24 cantilevers built on steel (EN 1.0570), six cantilevers on nickel-base alloy (René 80) and six on hot-working tool steel (AISI H13). After the completion of the LPBF process, an additional LMD layer of Inconel 718 is deposited onto each LPBF cantilever. Size effects on the resulting geometry were not considered [21].

The LMD experiments are conducted with a TruLaser Cell 7020 from Trumpf GmbH + Co. KG, Ditzingen, Germany. The machine contains a TruDisk $2.0 \mathrm{~kW}$ Yb:YAG laser and coaxial powder nozzle, which is orientated perpendicular to the LPBF substrate. The used powder has a particle size distribution of $45-90 \mu \mathrm{m}$. Helium 5.0 is used as carrier gas for the powder. With a fixed gas flow of $41 /$ $\mathrm{min}$, the powder mass flow is adjusted to $5.2 \mathrm{~g} / \mathrm{min}$. To avoid oxidation of the deposited Inconel 718, Argon 5.0 is utilized as shielding gas. The used process parameters, Table 2 , are attained from previous experiments and were optimized for low porosity while avoiding too much grain coarsening due to high energy input [22]. The resulting LMD track has a width of $1.85 \mathrm{~mm}$ and a track height of approximately $0.5 \mathrm{~mm} \mathrm{[22].}$

Thermocouples are attached to the outer endings of the cantilever for temperature measurement. In the next step,

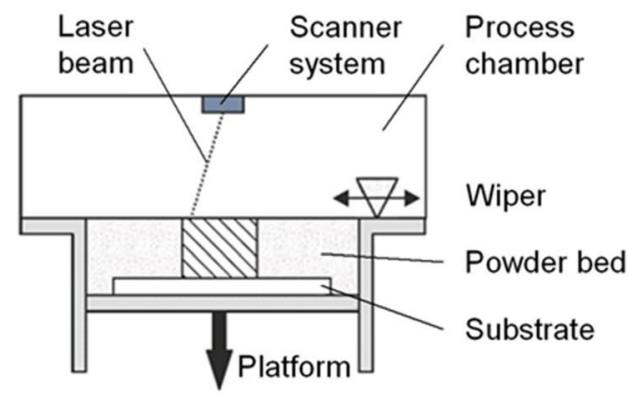

(a)

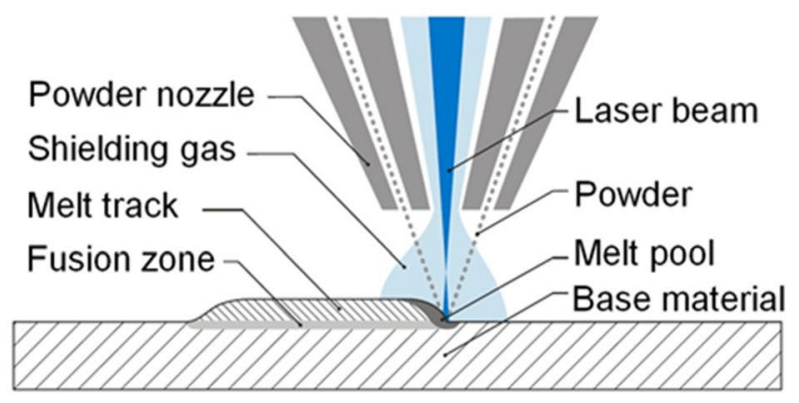

(b)

Fig. 1 Schematic illustration of the a LPBF process [6]; b LMD process [6]

Table 2 LPBF and LMD process parameters for Inconel 718 (UNS N07718)

\begin{tabular}{llllll}
\hline Process & Laser power & Velocity & Laser spot diameter & Hatch distance & Layer thickness \\
\hline LPBF & $275 \mathrm{~W}$ & $760 \mathrm{~mm} / \mathrm{s}$ & $0.18 \mathrm{~mm}$ & $0.12 \mathrm{~mm}$ & $0.05 \mathrm{~mm}$ \\
LMD & $750 \mathrm{~W}$ & $12.5 \mathrm{~mm} / \mathrm{s}$ & $1.0 \mathrm{~mm}$ & $1.22 \mathrm{~mm}$ & $0.5 \mathrm{~mm}$ \\
\hline
\end{tabular}

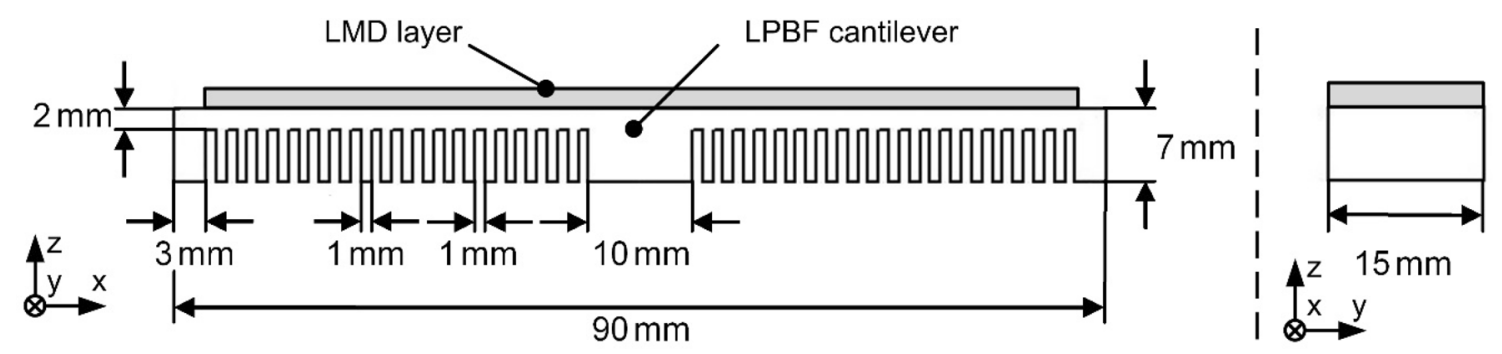

Fig. 2 Schematic illustration of the LPBF twin cantilever geometry with the deposited LMD layer, build direction along z-axis, build plane and EDM cutting plane along xy-plane 
a contour track is deposited with LMD onto the LPBF specimens. The contour is filled with three different hatch strategies, as pictured in Fig. 3a. The LMD hatch strategy is altered to study its influence on the resulting distortion. The longitudinal strategy $\mathrm{S} 1$ exhibits $80 \mathrm{~mm}$ long melt tracks parallel to the cantilever length whereas the transverse patterns S2 and S3 feature $12 \mathrm{~mm}$ long tracks perpendicular to the cantilever length. $\mathrm{S} 2$ is executed continuously from one cantilever end to the other, and strategy S3 is conducted bilaterally from the outer ends to the inner part. For strategy S1, a homogeneous heating of the cantilever is expected. However, the solidification and shrinking of the long, parallel tracks are expected to lead to a high residual stress and distortion. Less distortion is expected for the transverse patterns S2 and S3, accompanied by an unequal heat accumulation and temperature gradient for the two arms of the twin cantilever in case of S2. To achieve a more uniform heat input, S3 is applied bilaterally from both ends of the cantilever. The starting point of the laser exposure is varied each cantilever from left to right.

To study the influence of the different strategies S1, S2 and S3 on distortion, each LMD strategy is applied on eight identical cantilevers. To create the same LMD process conditions on each cantilever, the deposition of an LMD layer is started by the time the substrate cooled down to a temperature of $40{ }^{\circ} \mathrm{C}$. Some example LPBFLMD cantilevers are shown in Fig. 3b. Half of these cantilevers are exposed to a subsequent heat treatment. In total, 12 cantilevers are analysed in the as-built condition and 12 cantilevers are heat-treated, leading to four cantilevers for each of the three LMD hatch strategies.

\subsection{Heat treatment and analysis}

To achieve results under industrial process chain conditions, the stress relief for the hybrid Inconel 718 cantilevers is conducted with a standard heat treatment according to VDI 3405 [23]. Corresponding to the VDI standard, the cantilevers are still bonded to the build plate during the heating and cooling procedures. The heat treatment is conducted in a LH 60/13 chamber furnace from NABERTHERM GMBH, Lilienthal, Germany. The initial step is a solution heat treatment with a temperature of $T_{1}=980{ }^{\circ} \mathrm{C}$ for one hour. After air cooling to room temperature, the furnace is heated up again for a two-step artificial aging. The first step lasts $8 \mathrm{~h}$ at $T_{2}=720^{\circ} \mathrm{C}$ and is followed by a furnace cooling with a cooling rate of $4{ }^{\circ} \mathrm{C} / \mathrm{min}$. The second step follows with $T_{3}=620^{\circ} \mathrm{C}$ for $10 \mathrm{~h}$. The heat treatment process ends with an air cooling to room temperature.

The distortion measurements are conducted with the optical 3D surface metrology system MicroProf 100 from FRT GмвH, Bergisch Gladbach, Germany, before and after the wire electrical discharge machining (WEDM) of the cantilever arms. After WEDM of the two cantilever arms, the cantilever is still bonded to the steel substrate by the massive central support. The curvature of the wire-eroded sides is analysed by measuring the height of the cantilever every $50 \mu \mathrm{m}$.

\subsection{Thermal-mechanical analysis}

To support the discussion about the effects of residual stress development and the resulting distortion along the laser-based additive manufacturing process chain, FEMbased thermal-mechanical simulations were carried out using ANSYS Mechanical 19.0, ANSYS INC., Canonsburg, (a)

\section{s1}

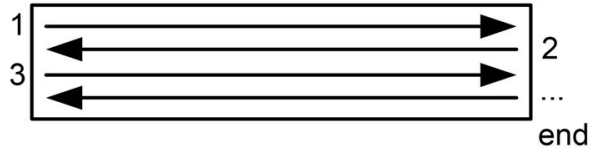

$2 \quad \cdots$

S2

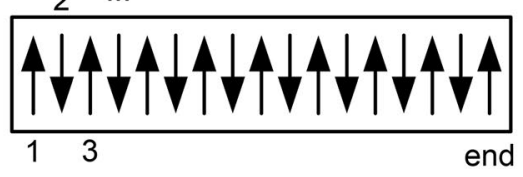

3

S3

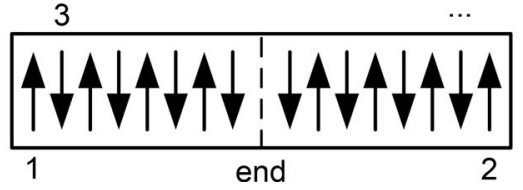

(b)

Longitudinal

Transverse, unilateral

Transverse, bilateral

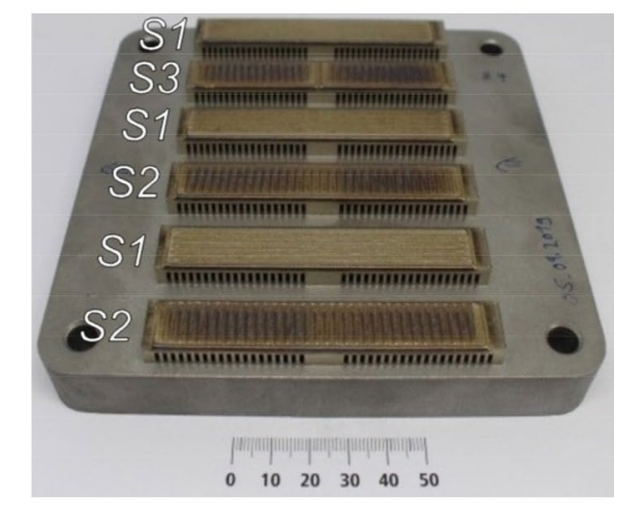

Fig. 3 Investigated LMD hatch strategies: a sample description with sequence of tracks indicated by numbers, equal distances of tracks; $\mathbf{b}$ asbuilt hybrid cantilevers on steel substrate 
Pennsylvania, USA. For each simulation, a build plate with the different materials from the experiments were coupled with one Inconel 718 cantilever and a static structural simulation of the heat-treatment was carried out. As a simplification, only the initial step of the solution heat treatment with $T_{1}=980{ }^{\circ} \mathrm{C}$, which is bound to relieve most of the residual stresses, was simulated and the coefficients of thermal expansion $\alpha$ were chosen for $T=500{ }^{\circ} \mathrm{C}$, Table 3 .

Table 3 Used coefficients of thermal expansion for $T=500{ }^{\circ} \mathrm{C}$

\begin{tabular}{lllll}
\hline Unit & $\begin{array}{l}\text { Nickel-base alloy } \\
\text { Inconel 718 }\end{array}$ & $\begin{array}{l}\text { Nickel-base alloy } \\
\text { René 80 }\end{array}$ & $\begin{array}{l}\text { Tool steel } \\
\text { H13 }\end{array}$ & $\begin{array}{l}\text { Steel } \\
1.0570\end{array}$ \\
\hline $10^{-6} / \mathrm{K}$ & 14.8 & 13.6 & 13.5 & 13.9 \\
\hline
\end{tabular}
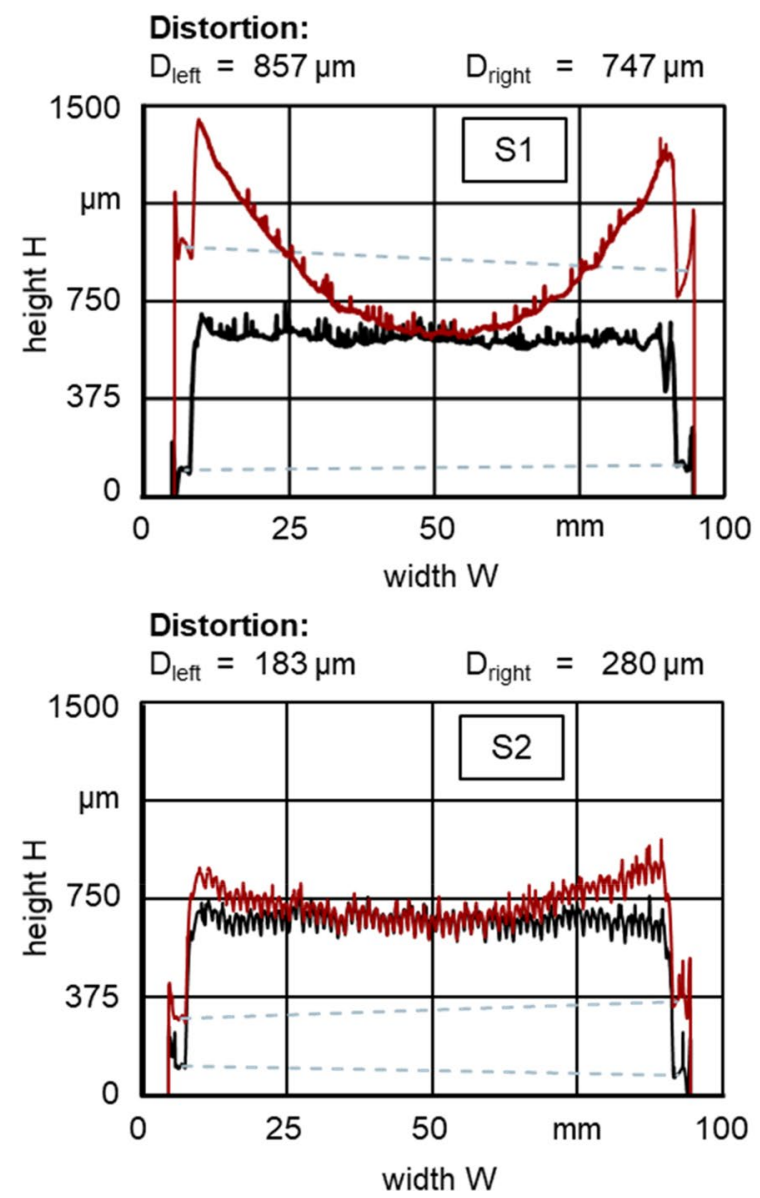

\section{Results}

\subsection{Effect of LMD hatch strategy on distortion}

The results of the curvature measurements before and after WEDM of the cantilever arms are pictured in Fig. 4 for each LMD strategy in the as-built condition.

Before WEDM, the twin cantilevers are flat, which is illustrated by the dashed line between the plateaus of the black measurement curve. The measurements after WEDM are illustrated in red. The slope of the dashed line connecting the red plateaus indicates an asymmetric distortion, which varies for the different LMD strategies. The vertical distance between the plateaus is measured on each side to quantify the distortion $D$. For each cantilever, the maximum distortion $D_{\max }$ for the different LMD hatch strategies is shown in Fig. 5.

\section{Process: \\ Hybrid LPBF-LMD \\ Material: \\ Workpiece Inconel 718 \\ Build plate $\quad 1.0570$ \\ Condition as-built \\ LMD hatch strategy: \\ S1 Longitudinal \\ S2 Transverse, unilateral \\ S3 Transverse, bilateral \\ Starting point right cantilever side}

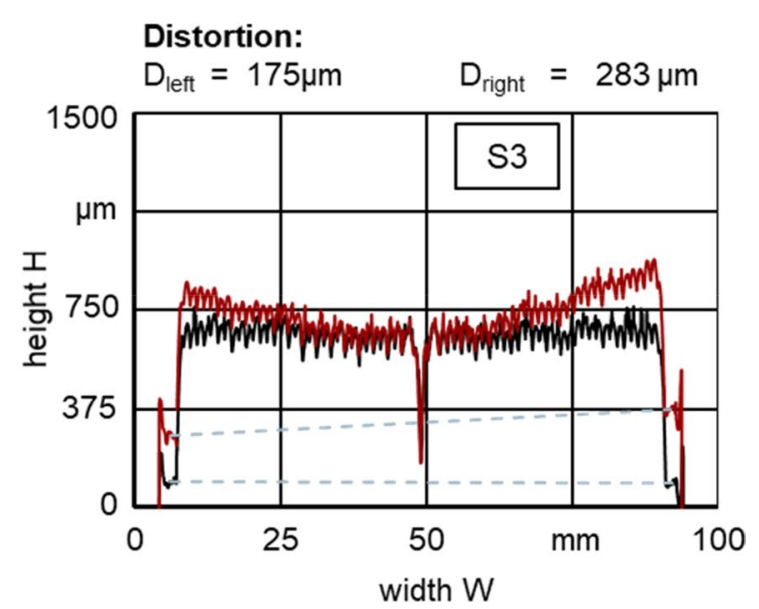

Fig. 4 Cantilever surface and distortion $D$ in the as-built condition for LMD strategies S1, S2, S3 


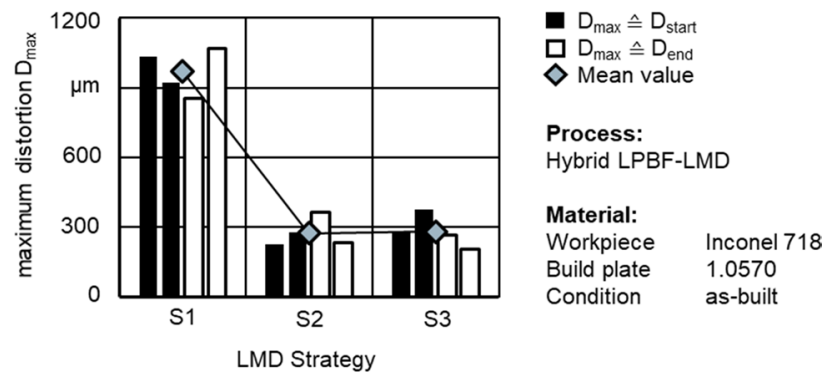

Fig. 5 Maximum distortion $D_{\max }$ of the as-built cantilevers for different LMD hatch strategies

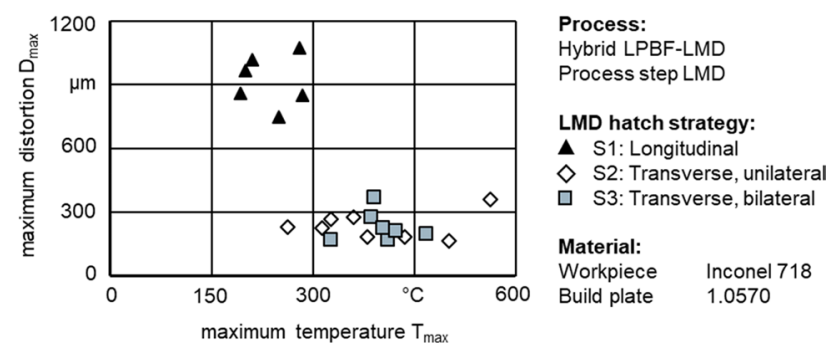

Fig. 6 Distortion D depending on temperature $T_{\max }$ of the cantilever arms in the as-built condition

The highest distortion is obtained with the longitudinal hatch strategy S1 with about $D_{\max , \mathrm{S} 1} \approx 1000 \mu \mathrm{m}$. This can be explained by the shrinking during solidification of the longitudinal tracks parallel to the concerned stress direction [24], which is more pronounced for the significantly longer LMD tracks for hatch strategy S1 compared to hatch strategies S2 and S3. This result is also consistent with the findings of PARIMI [10] for same material build plates, who measured the highest distortion with a longitudinal path strategy.

The distortions of the transversal patterns S2 and $\mathrm{S} 3$ are smaller and similar to each other with about $D_{\text {max }, \mathrm{S} 2} \approx D_{\text {max }, \mathrm{S} 3} \approx 300 \mu \mathrm{m}$. For pattern $\mathrm{S} 2$, the maximum distortion is always on the side of the LMD path starting point, which can be attributed to the low cantilever temperature at the beginning of the LMD process and the resulting high temperature gradients. During the LMD process, the cantilever temperature rises and the temperature gradient decreases, resulting in lower distortions at the end of the continuous track S2. For the LMD strategies S1 and S3, the maximum distortions are not always on the same side as the LMD starting point, indicating a more homogenous temperature distribution in the workpiece. These findings are supported by Fig. 6, in which the maximum distortion $D_{\max }$ is plotted with the maximum temperature at the corresponding cantilever ending.

The measured temperatures of cantilevers produced with strategy S1 are relatively low and scatter over a small temperature range compared to the other hatch strategies S2 and S3. This can be explained by a more balanced rate of heat input by the laser to heat output into the substrate along the cantilever material. However, the lower temperatures in the solid cantilever material lead to a higher temperature gradient towards the melt pool. This in turn leads to higher amounts of stresses and distortion due to the temperature gradient mechanism. In contrast, the maximum temperature range for the $\mathrm{S} 2$ cantilevers $\Delta T_{\mathrm{S} 2}=300{ }^{\circ} \mathrm{C}$ is broader and located at higher temperatures because of heat accumulation. Compared to strategy S2, the temperature range of the S3 cantilevers is smaller with $\Delta T_{\mathrm{S} 3}=140{ }^{\circ} \mathrm{C}$, due to the more even heat input along the cantilever with the bilateral deposition strategy S3.

\subsection{Effect of heat treatment and substrate material on distortion}

The curvature measurement of the cantilevers after heat treatment, which are exemplarily shown in Fig. 7, exhibit unexpected features. At first, the cantilevers are not ideally flat even before WEDM. Moreover, the cantilever arms are bending downwards after WEDM instead of staying at the same level as it would be the case for totally stress-relieved specimens, indicating induced stress.

However, the stresses initially induced by the LMD process are relieved or superposed, since the arms do not bend upwards after heat treatment, compared to the results illustrated in Fig. 4. The resulting maximum distortion $D_{\max }$ after the heat treatment is shown in Fig. 8 for each cantilever. In the diagram, the downward bending is indicated by the negative distortion values. In contrast to the as-built specimens, the maximum distortion after heat treatment is nearly the same for all LMD strategies, with $-170 \mu \mathrm{m} \geq D_{\max } \geq-307 \mu \mathrm{m}$.

It is important to notice that the cantilever arms are not touching the build plate after WEDM and thereby the relaxation is not constrained, Fig. 9. The similar distortion for strategies S1, S2 and S3 indicates that the heat treatment successfully eliminates the effect of the different LMD hatch strategies on the distortion. In conclusion, the heat treatment reduces the maximum distortion and the dependence from the applied LMD strategy.

While the influence of the LMD hatch strategy on the stress distribution and the resulting distortion could be reduced or even eliminated in the presented experiments by applying a heat treatment, additional stress was induced by the very same heat treatment. The discrepancy of distortion before and after heat treatment can be explained by additionally induced stress due to the deviant thermal expansion of the build plate and cantilever material. During the applied heat treatment, the cantilevers and the build plate are heated up and then held at high temperatures. When both cantilever and build plate temperature rises, the volumes are expanding 


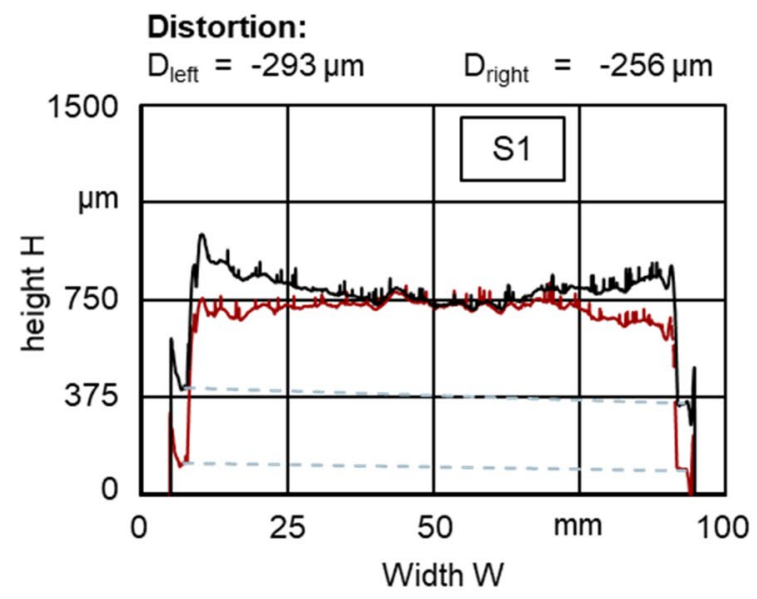

_ $\quad$ Surface after Wire-EDM

Process:

Hybrid LPBF-LMD

Material:

Workpiece Inconel 718

Build plate $\quad 1.0570$

Condition heat-treated

LMD hatch strategy:

S1 Longitudinal

S2 Transverse, unilateral

S3 Transverse, bilateral

Starting point right cantilever side
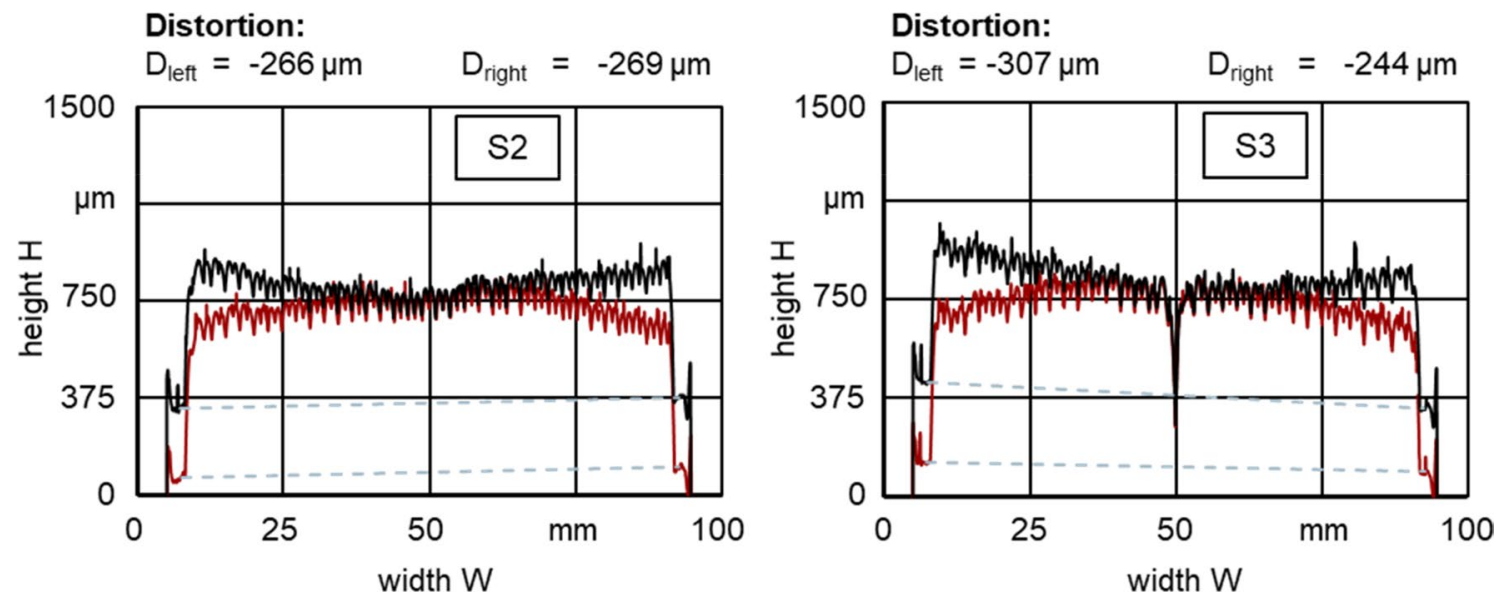

Fig. 7 Cantilever surface and distortion $D$ after heat treatment for LMD hatch strategies S1, S2, S3

Fig. 8 Maximum cantilever distortion $D_{\max }$ in the heat-treated condition for different LMD hatch strategies

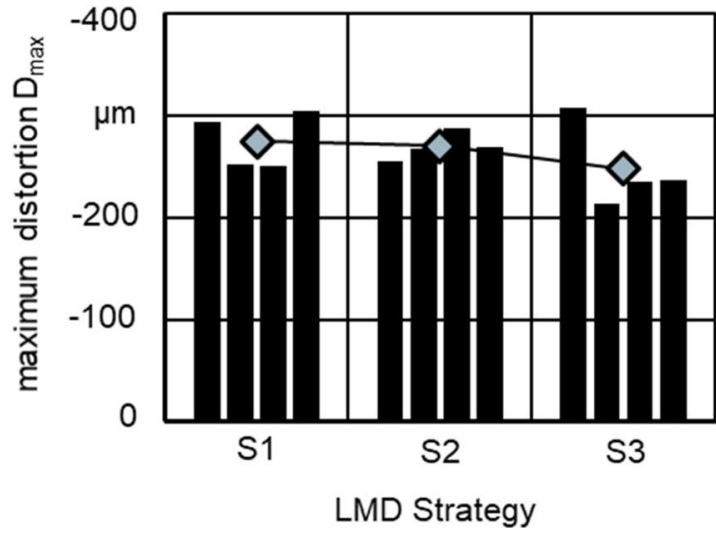

Mean value

Process:

Hybrid LPBF-LMD

Material:

Workpiece Inconel 718

Build plate $\quad 1.0570$

Condition heat-treatet corresponding to their coefficient of thermal expansion $\alpha$. The coefficient of thermal expansion $\alpha$ in general is higher for Inconel 718 than for steel 1.0570, Table 3. Due to the metallurgical bond between Inconel 718 cantilever and steel build plate, the thermal expansion of the cantilever is partly hindered, such that elastic strains and stresses are induced. When the temperature rises further, the yield strength of Inconel 718, which reduces at high temperatures, is exceeded in the cantilever and plastic strains are induced. This is especially the case at the end of both cantilever 


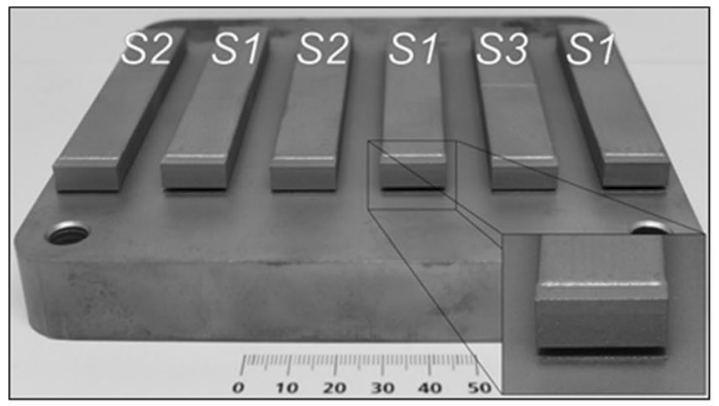

(a)

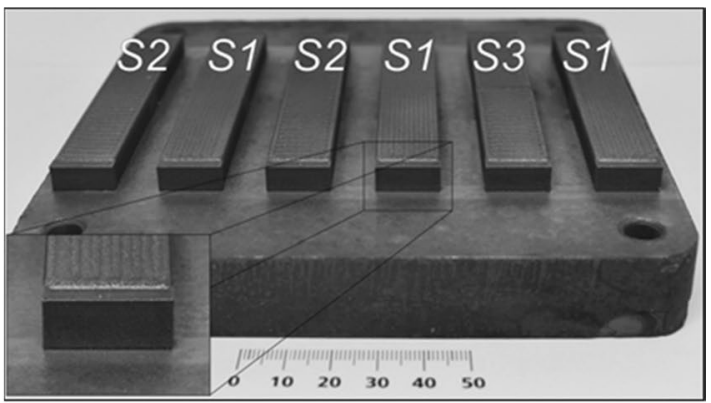

(b)

Fig. 9 Wire-eroded hybrid twin cantilever on 1.0570 substrate: a without heat treatment; $\mathbf{b}$ after heat treatment

arms. In Fig. 10, the principle of stress generation during the heat-treatment is shown with simulative results. The H13 steel build plate leads to stresses induced in the cantilever, Fig. 10a, b. Changing the build plate material to Inconel 718, the simulation shows no induced stresses, Fig. 10c. These results support the hypothesis, that the different thermal expansions of the build plate material and the workpiece material are responsible for the distortion behavior after heat treatment. It should be noticed that for the given heat treatment temperature of $T=980{ }^{\circ} \mathrm{C}$, the coefficient of thermal expansion $\alpha$ for Inconel 718 is actually higher than for $T=500{ }^{\circ} \mathrm{C}$, which was used for the simulation, leading to higher stresses and therefore plastic strain components. After heat treatment, when the temperature was reduced slowly to room temperature, compressive residual stresses remain where plastic tensile strains were induced, and tensile residual stresses remain where plastic compressive strains were induced during heat treatment. When the cantilevers are cut via WEDM, the cantilever arms are stress-relieved and bend downwards towards their equilibrium position during heat treatment.

In Fig. 11, the resulting distortion after heat treatment is shown for different build plate materials and their difference in coefficient of thermal expansion $\alpha_{500}{ }^{\circ} \mathrm{C}$ at a reference
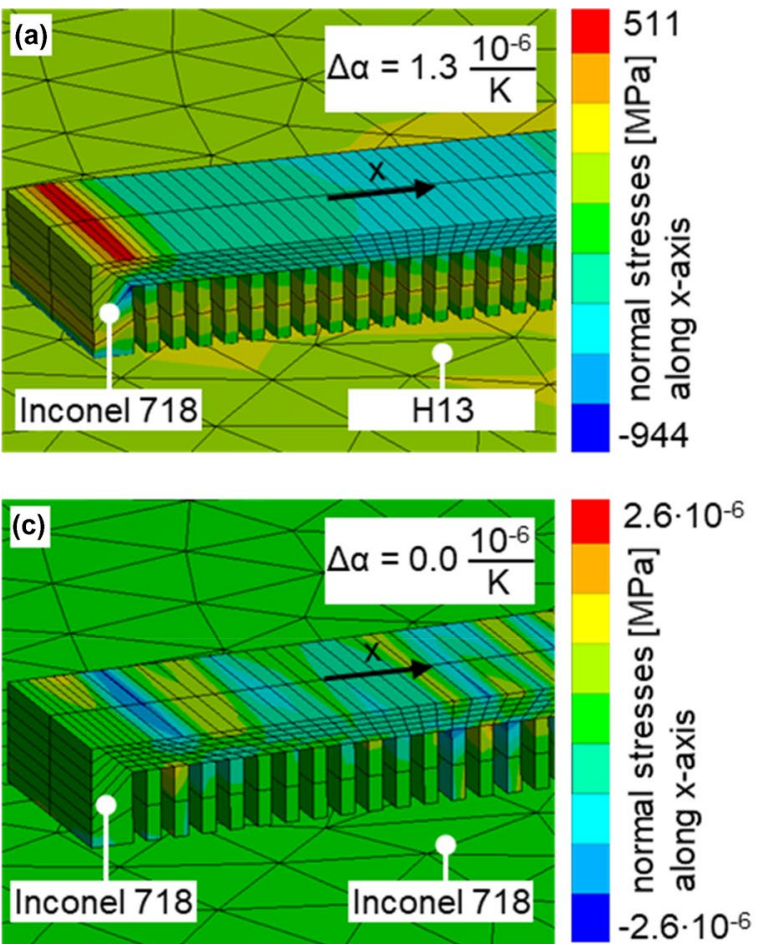
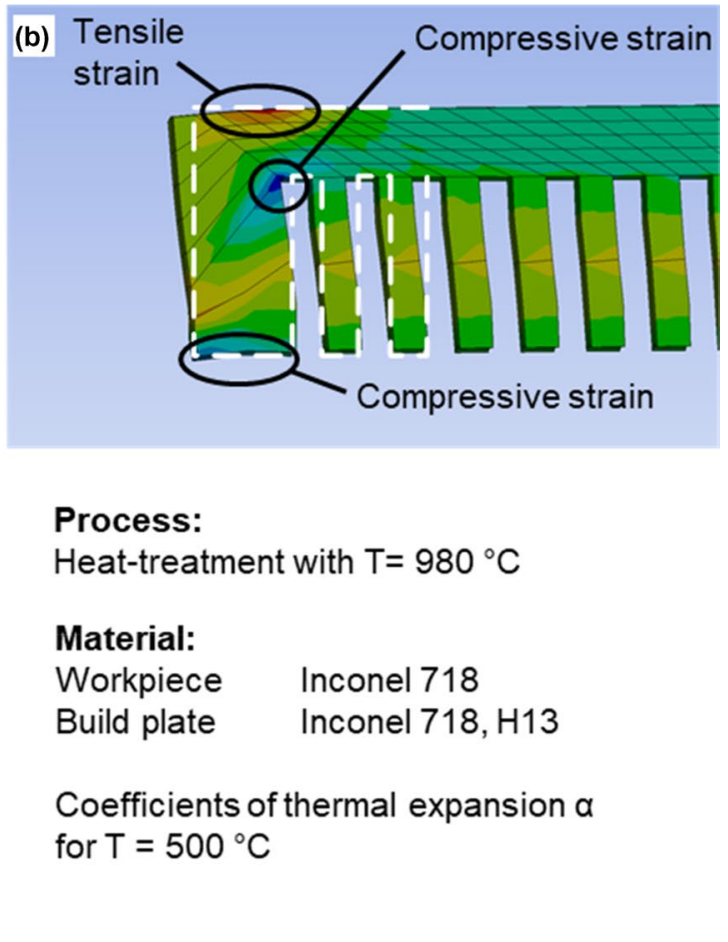

Fig. 10 Effects of thermal expansion on the stress generation during heat treatment: a deviant thermal expansion of build plate and cantilever; $\mathbf{b}$ induced strains; c equal thermal expansion of build plate and cantilever 
Fig. 11 Distortion at LMD starting point $D_{\text {start }}$ and ending point $D_{\text {end }}$ after heat treatment in relation to the build plate material and the corresponding coefficient of thermal expansion $\alpha$

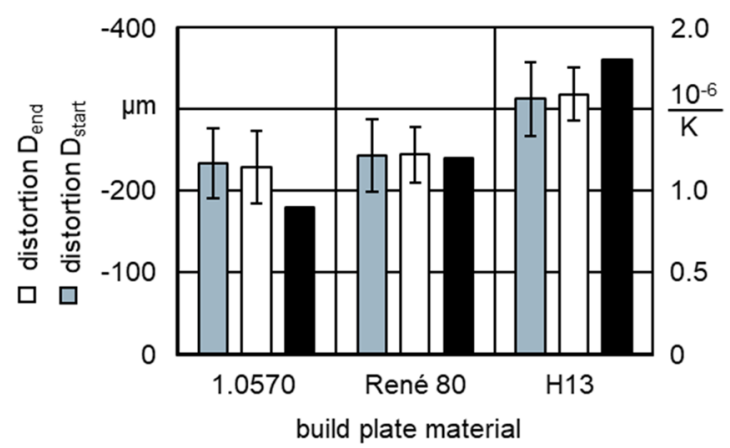

\author{
Process: \\ Hybrid LPBF-LMD \\ Material: \\ Workpiece Inconel 718 \\ Condition heat-treated \\ Coefficients of thermal expansion $\alpha$ \\ for $\mathrm{T}=500^{\circ} \mathrm{C}$ \\ LMD hatch strategy:
S1 Longitudinal
S3 Transverse, bilateral
}

temperature of $500{ }^{\circ} \mathrm{C}$. From the results, it can be derived that with increasing discrepancy between the coefficient of thermal expansion $\alpha$ of the build plate material and the workpiece material, the induced stresses, and therefore, the resulting distortions after heat treatment increase. Using an identical material for workpiece and substrate in a structural simulation did not result in notable induced stresses due to the heat treatment, and should therefore be adapted in processes where heat treatments are foreseen.

\section{Conclusions and outlook}

The distortion of hybrid LPBF-LMD specimens is investigated in dependence of different aspects along the process chain, including the applied LMD hatch strategy, and the influence of the build plate material in combination with a heat treatment after the additive manufacturing process. The distortion is measured with twin cantilevers in the asbuilt and heat-treated condition. Three LMD hatch strategies are investigated, including a longitudinal pattern $\mathrm{S} 1$, which exhibits long melt tracks parallel to the concerned stress direction, and two transverse patterns S2 and S3, where the LMD application is conducted continuously from one end to the other (S2) and bilaterally from the endings to the center (S3). The distortion for strategy S1 is about three times higher than for the transverse strategies S2 and S3. For the continuous pattern $\mathrm{S} 2$, the obtained deformation is asymmetrical due to the local heat accumulation accompanied by the descending temperature gradient, leading to a higher distortion on the cantilever side where the LMD process started. Pattern S3, where an exceeding heat accumulation is prevented, offers the most symmetrical distortion.

After the heat-treatment, the distortion is independent from the applied LMD strategy. Distortions are visible before and after eroding the cantilevers, indicating that the LMD-induced stress is relieved, but additional stresses are induced. These stresses are induced due to the difference in thermal expansion of the workpiece and build plate material, such that the thermal expansion of the workpiece is partially hindered until plastic strains are induced. Those plastic strains result in residual stresses after the workpiece has cooled down to room temperature. If a heat treatment is foreseen in the process chain of a laser-based additive manufactured part, the build plate material should match the part material regarding the coefficient of thermal expansion.

Further experiments are planned, which will focus on the influence of grain size gradients in the workpiece due to the hybrid additive manufacturing approach on the resulting deformation.

Acknowledgements This paper is based on results acquired in the project 378970463 , which is kindly supported by the Deutsche Forschungsgemeinschaft (DFG).

Author contributions Supervision, conceptualization, EU; Methodology, LPBF experiments, writing-original draft preparation, JD; Simulation and distortion analysis: EK; LMD experiments, TP; Supervision, writing-review and editing, MR; writing-review and editing, BG; All authors have read and agreed to the published version of the manuscript.

Funding Open Access funding enabled and organized by Projekt DEAL. This work was supported by the Deutsche Forschungsgemeinschaft (DFG) [project number 378970463].

Data availability The data that support the findings of this study are available from the corresponding author upon reasonable request.

\section{Compliance with ethical standards}

Conflict of interest The authors declare that they have no conflict of interest.

Open Access This article is licensed under a Creative Commons Attribution 4.0 International License, which permits use, sharing, adaptation, distribution and reproduction in any medium or format, as long as you give appropriate credit to the original author(s) and the source, provide a link to the Creative Commons licence, and indicate if changes were made. The images or other third party material in this article are included in the article's Creative Commons licence, unless indicated otherwise in a credit line to the material. If material is not included in the article's Creative Commons licence and your intended use is not permitted by statutory regulation or exceeds the permitted use, you will need to obtain permission directly from the copyright holder. To view a copy of this licence, visit http://creativecommons.org/licenses/by/4.0/. 


\section{References}

1. Wohlers T (2019) Wohlers report 2019: 3D printing and additive manufacturing state of the industry. WOHLERS Associates, Fort Collins

2. EOS GmbH-Electro Optical Systems, 2016. Material data sheet-FlexLine, EOS Nickel Alloy IN718, Manufacturer specification.

3. Buchbinder D, Schleifenbaum H, Heidrich S, Meiners W, Bültmann J (2011) High power selective laser melting (HP SLM) of aluminium parts. Phys Procedia 12:271-278

4. Bremen S, Buchbinder D, Meiners W, Wissenbach K (2011) Mit Selective Laser Melting auf dem Weg zur Serienproduktion? Laser Tech J 8(6):271-278

5. Kaierle S, Barroi A, Noelke C, Hermsdorf J, Overmeyer L, Haferkamp H (2012) Review on laser deposition welding: from micro to macro. Phys Procedia 39:336-345

6. Graf, B.; Schuch, M.; Kersting, R.; Gumenyuk, A.; Rethmeier, M.: Additive Process Chain using Selective Laser Melting and Laser Metal Deposition. Proc. of the Lasers in Manufacturing Conference (LIM) 2015.

7. Petrat T, Graf B, Gumenyuk A, Rethmeier M (2016) Laser metal deposition as repair technology for a gas turbine burner made of Inconel 718. Phys Procedia 83:761-768

8. Uhlmann, E.; Düchting, J.; Petrat, T.; Graf, B.; Rethmeier, M.: Heat treatment of SLM-LMD hybrid components. Proceedings of the Lasers in Manufacturing Conference (LIM) 2019.

9. Liu Q, Wang Y, Zheng H, Tang K, Ding L, Li H, Gong S (2016) Microstructure and mechanical properties of LMD-SLM hybrid forming Ti6Al4V alloy. Mater Sci Eng, A 660:24-33

10. Parimi LL, Attallah MM, Gebelin J, Reed RC (2012) Direct Laser Fabrication of Inconel-718: effects on distortion and microstructure. In Superalloys 2012 Huron ES, Reed RC, Hardy MC, Mills MJ, Montero RE, Portella PD, Telesman J (eds). https://doi. org/10.1002/9781118516430.ch56

11. Nadammal N, Kromm A, Saliwan-Neumann R, Fahrabod L, Haberland C, Dolabella Portella P (2018) Influence of support configurations on the characteristics of selective laser melted Inconel 718. Jom 70:343-348

12. Wolff SJ, Gan Z, Lin S, Bennett JL, Yan W, Hyatt G, Ehmann KF, Wagner GJ, Liu WK, Cao J (2020) Experimentally validated predictions of thermal history and microhardness in laser-deposited Inconel 718 on carbon steel. Addit Manuf 27:540-551

13. Wang X, Chou K (2017) Electron backscatter diffraction analysis of Inconel 718 parts fabricated by selective laser melting additive manufacturing. Jom 69:402-408
14. Cheng Y, Xiao Z, Zhu H, Zeng X, Wang G (2019) Influence of substrate characteristics on residual stress of SLMed Inconel 718. Rapid Prototyp J 25(4):792-799

15. Gao M, Wang Z, Li X, Zeng X (2013) The effect of deposition patterns on the deformation of substrates during direct laser fabrication. J Eng Mater Technol 135:034502

16. Nazemi N, Urbanic RJ (2018) A numerical investigation for alternative toolpath deposition solutions for surface cladding of stainless steel P420 powder on AISI 1018 steel substrate. Int J Adv Manuf Technol 96:4123-4143

17. Salem M, Le Roux S, Hor A, Dour G (2020) A new insight on the analysis of residual stresses related distortions in selective laser melting of Ti-6Al-4V using the improved bridge curvature method. Addit Manuf 36:101586

18. Zongo F, Simoneau C, Timercan A, Tahan A, Brailovski V (2020) Geometric deviations of laser powder bed-fused AlSi10Mg components: numerical predictions versus experimental measurements. Int J Adv Manuf Technol 107:1411-1436

19. Barros R, Silva FJG, Gouveia RM, Saboori A, Marchese G, Biamino S, Salmi A, Atzeni E (2019) Laser powder bed fusion of Inconel 718: residual stress analysis before and after heat treatment. Metals 9:1290

20. El-Sari B, Biegler M, Graf B, Rethmeier M (2020) Distortionbased validation of the heat treatment simulation of directed energy deposition additive manufactured parts. Procedia CIRP 94:362-366

21. Fotovvati B, Asadi E (2019) Size effects on geometrical accuracy for additive manufacturing of Ti-6Al-4V ELI parts. Int J Adv Manuf Technol 104:2951-2959

22. Petrat T, Brunner-Schwer C, Graf B, Rethmeier M (2019) Microstructure of Inconel 718 parts with constant mass energy input manufactured with direct energy deposition. Procedia Manuf $36: 256-266$

23. VDI guideline 3405 Part 2.2, 2017. "Laser beam melting of metallic parts. Material data sheet nickel alloy material number 2.4668

24. Mugwagwa L, Dimitrov D, Matope S, Yadroitsev I (2019) Evaluation of the impact of scanning strategies on residual stresses in selective laser melting. Int J Adv Manuf Technol 102:2441-2450

Publisher's Note Springer Nature remains neutral with regard to jurisdictional claims in published maps and institutional affiliations. 